\title{
Organization of the Ph-doctoral studies on the chemical specialties
}

\author{
Sagdat, Tazhibayeva'; Grigoryi, Mun'; Galiya, Irmukhametova ${ }^{\mathrm{a}}$; Yerdos, \\ Ongarbayev $^{\text {a }}$ Zhannur, Myltykbaeva ${ }^{a}$ and Altynai, Musabekova ${ }^{a}$ \\ ${ }^{a}$ Department of chemistry and chemical technology, Al-Farabi Kazakh National University, \\ Kazakhstan.
}

\begin{abstract}
Problem of globalization of the educational process and integration into the international educational space is one of the most urgent problems for the Kazakh universities. In this regard, generalization of experience in training of PhD students is of particular interest, since training of PhD students is different in different countries. The example of the organization of educational process and scientific research in the PhD studies of chemical specialties at Faculty of Chemistry and Chemical Technology Al-Farabi Kazakh National University shows the peculiarities of the organization and defense of dissertations in Kazakhstan universities.

It is shown that the training of specialists - doctoral students at Kazakhstan universities is carried out on the basis of theoretical and practical tests. At the same time currently the state of theoretical training and practical research is 1:1,5 however there is a tendency of decrease of the theoretical training.

Conditions for preparation and defense of PhD-dissertations are described. The main requirements for the defense are marked: fulfillment of theoretical training and practical research in amount of 75 credits, the publication of results in journals with non-zero impact factor and approbation of the results in international scientific conferences.
\end{abstract}

Keywords: modules; credits; Ph-doctoral students; curriculum; dissertation. 


\section{Introduction}

One of the most important modern trends of economic development is internationalization and with respect to higher education is expressed in student and teacher mobility, internationalization of curricula and programs, establishment of regional and international university networks, export of educational services and related problems of the quality of education and international accreditation [1,2]. Since 2010, Kazakhstan became the 47th country that along with European countries began to carry out studies at universities by the principles of Bologna process. This assumes, first of all, the transition to 3-level model of training; academic mobility of students and teachers; the transition to a system of quality assessment of education through accreditation and academic ranking of universities [1-3].

The transition to a three-stage education in higher education institutions of Kazakhstan is a fait accompli. By the results of 2015 in the QS rankings of universities Al-Farabi Kazakh National University takes 275th place. Since 2005, National Universities of Kazakhstan began training in Ph-doctoral studies. The purpose of this article is an analysis of organization of classes, research and defense of the thesis for Ph-doctoral universities in the chemical specialties of Kazakhstan.

\section{Main part}

The distinctive feature of organization of classes in the $\mathrm{Ph}$-doctoral studies at the universities of Kazakhstan is the presence of theoretical training and the implementation of research into practice. Therefore, Kazakh National University pays great attention to the preparation of curricula, including theoretical training, as well as research work. Let us consider this on an example of the curriculum of specialty "Chemistry" in Al-Farabi Kazakh National University.

$\mathrm{Ph}$-doctoral students training on specialty "Chemistry" goes in two directions: "Basic Chemistry" and "Applied Chemistry" (Table 1). 
Table 1. Content of curriculum of specialty "Chemistry"

\begin{tabular}{|c|c|c|c|}
\hline № & Main blocks & Name od modules & Number of credits \\
\hline \multirow[t]{2}{*}{1} & \multirow[t]{2}{*}{ Fundamental disciplines } & Compulsory state modules & 3 \\
\hline & & Compulsory professional modules & 15 \\
\hline \multirow[t]{5}{*}{2} & \multirow[t]{5}{*}{ Specialization disciplines } & \begin{tabular}{|l}
$\begin{array}{l}\text { Modules of individual educational } \\
\text { paths }\end{array}$ \\
\end{tabular} & \multirow[t]{5}{*}{18} \\
\hline & & \begin{tabular}{|l|} 
paths 1 \\
\end{tabular} & \\
\hline & & paths 2 & \\
\hline & & paths 3 & \\
\hline & & paths 4 & \\
\hline \multirow[t]{3}{*}{3} & \multirow[t]{3}{*}{ Additional types of training } & Professional practice & 6 \\
\hline & & Research work and final thesis & 28 \\
\hline & & Thesis preparation and defense & 5 \\
\hline & & Total & 75 \\
\hline
\end{tabular}

Taught component of curriculum includes "Fundamental disciplines" and "Disciplines of specialization". Fundamental disciplines consists of 18 credits, 3 of them are taken by "Compulsory state module" and 15 credits are assigned for "Compulsory professional module".

Discipline of Compulsory state module "Theory and problems of physical chemistry" is studied in both directions: in the "Fundamental chemistry" and "Applied chemistry".

Compulsory professional module includes subjects on modern aspects of radiation and polymer chemistry, colloid, analytical and biological chemistry, problems of catalysis and petrochemistry, chemical physics, etc.

$\mathrm{PhD}$ students study specialization disciplines by 4 individual trajectories. At this block $\mathrm{PhD}$ students study 6 disciplines, each one of them includes 3 credits, total 18 credits.

Block "Additional types of training" includes parts "Professional practice" (6 credits), "Research work and preparation of dissertation" (28 credits) and "Final dissertation" (5 credits).

Altogether curriculum of $\mathrm{PhD}$ specialty "Chemistry" includes 75 credits, 36 credits takes theoretical learning. However, it is necessary to specify the ratio of Kazakhstan credits to ECTS credits (Table 2). Given the fact that the ratio of Kazakhstan credits to ECTS credits is $1: 1.5$ [1], it is possible to approve, that the total number of credits mastered while studying at $\mathrm{PhD}$ Doctoral studies is $(75 \cdot 1.5)=112.5$.

Table 2. The ratio between Kazakhstan credits and ECTS credits

\begin{tabular}{|l|l|}
\hline 1 credit & $\begin{array}{l}45 \text { hour= 15 hour cur.+15 hour IWS+15 hour } \\
\text { IWSL }\end{array}$ \\
\hline 1 ECTS credit & $\begin{array}{l}25-30 \text { hour }=12,5-15 \text { hour cur. }+12,5-15 \text { hour } \\
\text { extracur. }\end{array}$ \\
\hline
\end{tabular}

The second feature of organization of classes in doctoral studies - every year decrease of the period of theoretical training. If earlier doctoral students passed theoretical training during the first 2 years, now that period is 1.5 years. From 2016-2017 academic year, the ratio of theoretical and practical training will be changed in the direction of increasing of 
the share of practical work. Moreover, the period of theoretical training will be 1 year (2 semesters of 15 weeks).

It is necessary to note, that not all countries include theoretical instruction into the doctoral program. For example, in the UK universities there are optional courses for PhD students, which are recommended to visit at the doctor's degree. These courses are devoted for the organization and planning of scientific research, exploration of new computer programs, etc. The main time $\mathrm{PhD}$ students use for scientific research. A similar provision in the training of scientific personnel is observed in Russian universities. Young scientists pass exams there on the specialty and one foreign language (mostly english), which gives them access to defense of the thesis in the presence of relevant publications [4].

At the same time in Hungary universities according to the curriculum of PhD some time is allocated for theoretical instruction. As in Kazakhstan universities, in Hungary universities $\mathrm{PhD}$ studies take 3 years or 6 semesters, during which students learn 180 credits. Among them 100 credits are engaged in the thesis preparation and 80 credits devoted to the theoretical courses, preparation of publications, patents and teaching practice. In this case, only the special courses, such as, Spectroscopy, Structure Investigated Methods are studied and no basic courses. PhD students select the elective courses depending on the dissertation topic. As in Kazakhstan universities, PhD students in Hungary are also involved in teaching activities.

Regarding the organization of defense of the thesis there are 3 Dissertation Councils on Faculty of Chemistry and Chemical Technology, where the defense of dissertations is held in the following directions of chemistry [5]:

1. Chemistry; Ecology (chemical and technical sciences);

2. Chemical technology of inorganic substances, chemical technology of organic substances;

3. Nanomaterials and Nanotechnology.

Each year about 10 people defend dissertations in the Dissertation Council on specialties "Chemistry" and "Ecology" (Table. 3). They are PhD graduates of Al-Farabi Kazakh National University and other universities in Kazakhstan.

Table 3. Number of defended dissertations at the Faculty of Chemistry and Chemical Technology of Al-Farabi Kazakh National University

\begin{tabular}{|l|l|l|l|l|l|}
\hline Specialization & 2011 year & 2012 year & 2013 year & 2014 year & 2015 year \\
\hline Chemistry & 7 & 7 & 7 & 3 & 7 \\
\hline Ecology & - & - & 1 & 5 & 5 \\
\hline $\begin{array}{l}\text { Chemical technology of } \\
\text { inorganic substances }\end{array}$ & - & - & 2 & 4 & 5 \\
\hline $\begin{array}{l}\text { Chemical technology of } \\
\text { organic substances }\end{array}$ & - & - & 1 & 4 & 3 \\
\hline $\begin{array}{l}\text { Nanomaterials and } \\
\text { nanotechnology }\end{array}$ & - & - & - & 6 & 8 \\
\hline
\end{tabular}

Dissertations are devoted to actual problems of catalysis, analytical and colloid chemistry, electrochemistry, preparation of new catalysts, creation of polymer materials for medicine, flocculants for wastewater treatment, development of methods for soil remediation, methods of analysis for radiation safety of population, development of assessment methods 
of soil contamination, evaluation of human impact on the environment of oil and industrial regions of Kazakhstan.

The requirement for admission to the defense of $\mathrm{PhD}$ students is mastering of the curriculum, implementation of the research timetable and publication of the results in journals from the List of periodicals recommended by the Ministry of Education of Kazakhstan, and in journals which have impact factor and included in the database of Thomson Reuters and Scopus. Furthermore, PhD students must approve research results at international conferences.

One of the factors of integration into the international educational space of training process of doctoral students is the fact that one of the consultants of $\mathrm{PhD}$ student is a foreign scientist with an experience in the field of studies of this $\mathrm{PhD}$ student in whose laboratory the doctoral student carries out research for a minimum of 4 months. For that, he must have an appropriate level of English. It should be noted that in the preparation of curricula authors study the curricula of the leading European universities and take over their experience. Based on the analysis of KazNU and other countries we can conclude that in the $\mathrm{PhD}$ program of al-Farabi Kazakh National University it is necessary to reduce the share of theoretical education for a corresponding increase of the labor input, spent on the implementation of the research work. Further work on the improvement of $\mathrm{PhD}$ students training will be aimed at the globalization of curricula and the training of specialists capable of working anywhere in the world.

\section{References}

Kozhevina O.V.(2010). Integration of Russian universities in the international educational space. International Journal of experimental education, 5, 75.

Omirbaev S. (2014). Successful integration of university in the international educational space. Version.

Vasiliev A.V. (2014). Pecularities of development of multi-level system of higher Education in Russia on the basis of integration to international educational space. J.Vector of Science of Tolijatti State University. 1,27.

Zakirova, G.D. (2010). Internationalization of accreditation in the high education system of Kazakhstan. In book: Integration of high education of Kazakhstan in the international educational space: achivements, problems and features, Almaty, 100. 